\title{
Multi-scale Assessment of the Environmental Impact of Refugee Camps in the Context of Climatic Variability
}

\author{
Olaf Kranz ${ }^{1,2}$, Elisabeth Schoepfer ${ }^{3}$, Kristin Spröhnle ${ }^{3}$ and Stefan Lang ${ }^{1}$ \\ ${ }^{1}$ Interfaculty Department of Geoinformatics - Z_GIS, University of Salzburg, Austria \\ ${ }^{2}$ Helmholtz Association Head Office, Berlin/Germany·Olaf.Kranz@helmholtz.de \\ ${ }^{3}$ German Aerospace Center (DLR), Oberpfaffenhofen/Germany
}

Short paper

\begin{abstract}
In this extended abstract the authors examine advantages and limitations of the use of Earth observation (EO) data for the assessment of environmental impact in the surroundings of refugee/internally displaced person (IDP) camps. Different methodological approaches on multiple spatial scales to identify environmental changes are evaluated and discussed. Thereby different influencing factors such as phenological stages, inter-annual climatic variability, as well as climate change are deliberated. Furthermore, consideration of needs and demands are made.
\end{abstract}

\section{Refugees and Their Impact on the Environment}

At a global scale, more than 51.2 million displaced people have been estimated by the UN Refugee Agency at the end of 2013 (UNHCR 2014). Locally growing population densities, such as in rapidly growing settlements as well as in refugee and IDP camps, are associated with significantly increasing pressure on natural resources (TEARFUND 2007, UNEP 2007). Deforestation, land degradation, as well as unsustainable use and pollution of water resources are, among others, the most significant effects associated with human impact in the vicinity of refugee/IDP camps. Since humanitarian assistance rarely provides a source of energy for cooking, displaced people are forced to find fuelwood in the surrounding area of their camp. This also applies for timber to construct temporary dwellings in case no formal accommodation is provided by relief organisations (UNEP 2007). This environmental degradation may also lead to an intensification of regional conflicts (BENJAMINSEN et al. 2012, BRONKHORST 2011), which undermine the effectiveness of relief efforts (TEARFUND 2007, UNEP/OCHA 2004). Thus, relief organisations try to mitigate these impacts by taking environmental considerations into account at the earliest stage possible (UNEP/OCHA 2014).

\section{Impact Assessment from Space}

Substantiated by several studies (KRANZ et al. 2015, HAGENLOCHER et al. 2012, KRANZ et al. 2010, SPRÖHNLE et al. 2010) the hypothesis is that the long-lasting local concentration of population has a strong impact on the environment in the vicinity of refugee/IDP camps,

GI_Forum - Journal for Geographic Information Science, 1-2015.

(C) Herbert Wichmann Verlag, VDE VERLAG GMBH, Berlin/Offenbach. ISBN 978-3-87907-558-4.

(C) ÖAW Verlag, Wien. ISSN 2308-1708, doi:10.1553/giscience2015s416. 
and that areas of significant human impact can be verified with remote sensing data. This feasibility study focusses on the assessment of approaches using multi-scale satellite data to derive reliable information about the environmental situation in the vicinity of the IDP camps in the area of Zalingei, Darfur region in Western Sudan (see figure 1).
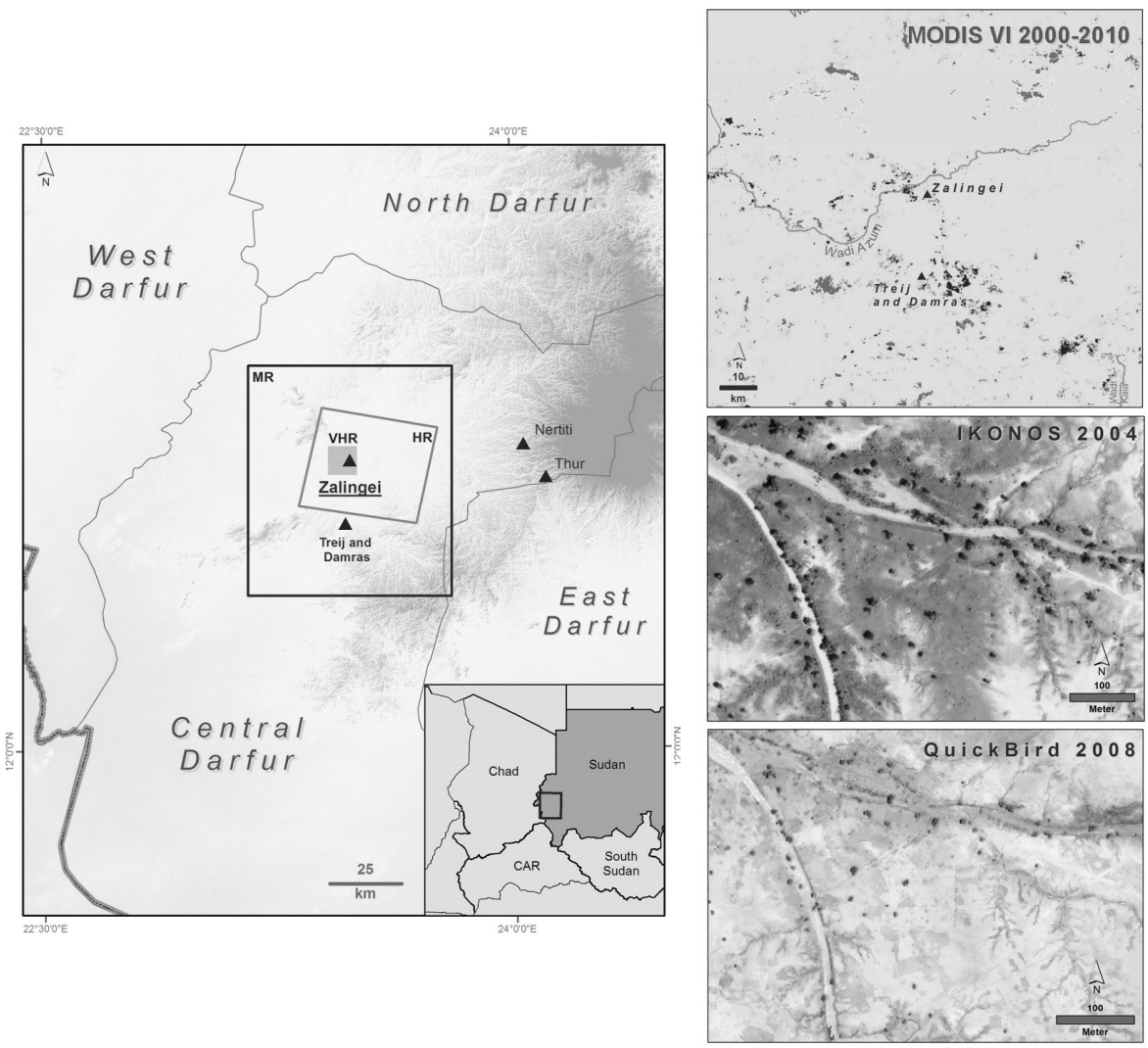

Fig. 1: Multi-scale satellite image analysis approach. Left: Overview on study sites at different scales $(\mathrm{MR}=$ Medium Resolution, $\mathrm{HR}=$ High Resolution, VHR $=$ Very High Resolution); right: trend pattern on MR (above), removal of trees and shrubs on VHR imagery between 2004 (middle) and 2008 (below).

Three different studies are analysed and compared in terms of their applicability: (1) monitoring of land cover changes using a time series of vegetation indices derived from medium resolution (MR) satellite data for the identification of hot spots of land cover changes (KRANZ et al. 2015); (2) detection of broad vegetation categories using high resolution (HR) SPOT data as well as (3) separation of woody vegetation features using very high resolution (VHR) QuickBird and IKONOS imagery (SPRÖHNLE et al. 2010). Figure 1 shows the multi-scale satellite image analysis approach. The trend pattern resulting from the MR time series analysis shows measurable trends in vegetation cover, indicating significant long-term land-cover changes. In general, both positive and negative trends are visible, representing an increase or decrease in vegetation cover over a decade. The derived 
hotspots are located either in areas with specific characteristics, i.e. near wadi banks or within the vicinity of settlements and IDP camps. A correlation of these trend patterns with precipitation, temperature, and population data indicates the influence of increasing population on natural resources such as trees and shrubs during the time of observation. Looking at the results of the change detection of HR SPOT imagery between 2003 and 2007, the trend pattern also suggests negative and positive changes in woody vegetation. Nevertheless, the influence of the IDP camps around Zalingei is not that obvious. The precipitation data reveal that the change detection results are influenced by different precipitation and consequent phenological conditions at the time of data acquisition. For a more profound statement on the causes of the negative trends detected with the SPOT images, a detailed assessment of changes derived from the analysis of VHR data seems to be necessary. The land degradation becomes evident when comparing the VHR data of 2004 and 2008, which obviously show a decline of woody vegetation in the surroundings of the IDP camps.

\section{Discussion and Outlook}

The results outlined above of analyses at different scales suggest some advantages and limitations of the approaches and data used. At all scales both decreases and increases in vegetation cover can be detected. These changes are influenced by a complex mix of interacting factors including human impact, groundwater availability, as well as fluctuating climatic parameters due to natural variability and climate change. Accordingly, it is hard to clearly separate these different influencing factors from each other (SEAQUIST et al. 2009, WESSELS et al. 2007). Overall, positive trends might result from increasing fallow land, indicating a recovery of vegetation in consequence of less pressure on shrubs and trees, as well as grazing land (GEBRESENBET 2009, OLSSON et al. 2005, SCHIMMER 2008). Furthermore, this might be an indication for the forced displacement of residents and increasing rural-to-urban migration. Two further factors are an intensification of agriculture, and the recent greening of the Sahel (OLSSON et al. 2005, SEAQUIST et al. 2009). In contrast, decreasing precipitation or declining air temperatures might result in decreasing vegetation cover, including both natural vegetation and crops. This partly explains the detected negative trends in vegetation index values and vegetation cover. However, the trend pattern in conjunction with population figures suggests increasing pressure on the limited natural resources as the main factor for the negative trend as a result of the growth of settlements. The dramatic increase in displaced persons in and around Zalingei starting in 2004, and subsequent continuously high numbers of human population in the respective camps can be linked to the observed changes in vegetation cover. Logging of trees and removal of shrubs used as fuel wood, as well as building timber and fodder for livestock (UNEP 2007), are a consequence of the increasing population pressure (cf. KRANZ et al. 2015, 2010, HAGENLOCHER et al. 2012, SPRÖHNLE et al. 2010). We substantiate the following four facts already outlined by KRANZ et al. 2015: (1) the observed variability of climatic parameters is not strong enough for the pronounced land cover changes; (2) decreases in vegetation cover are remarkably high in the vicinity of camps, which is also underlined by other studies (AliX-GARCiA et al. 2013, HAGENLOCHER et al. 2012, KRANZ et al. 2010, UN SUdAN 2010, SCHIMMER 2008, UNEP 2007); (3) the complete removal of trees and shrubs notably close to camps becomes obvious on the VHR images; (4) if climatic parameters were the main influencing factor one would expect a less pronounced decrease in vegetation cover around camps. Thus, we conclude that the climatic variability has substantial impact but is 
not the major (or even singular) driver to changes in the vicinity of camps. Quantifying the respective contributions of the different factors to this multidimensional change phenomenon is subject to further studies.

\section{References}

AliX-Gracia, J., BArlett, A. \& SAAH, D. (2013), The Landscape of Conflict: IDPs, aid, and land use change in Darfur. Journal of Economic Geography, 13/4, 589-617.

Benjaminsen, T. A., Alinon, K., Buhaug, H. \& Buseth, J. T. (2012), Does climate change drive land-use conflicts in the Sahel? Journal of Peace Research, 49/1, 97-111.

BronkHORst, S. (2011), Climate Change and Conflict: Lessons for Conflict Resolution from the Southern Sahel of Sudan. ACCORD.

Gebresenbet, F. (2009), Climate and vegetation changes in the Sahel. In: LEROY, M (Ed.), Environment and Conflict in Africa. University for Peace, Addis Ababa, Ethiopia.

HAgENlocher, M, LANG, S. \& TIEDE, D. (2012), Integrated assessment of the environmental impact of an IDP camp in Sudan based on very high resolution multi-temporal satellite imagery. Remote Sensing of Environment, 126, 27-38.

KranZ, O., SACHS, A. \& LANG, S. (2015), Assessment of environmental changes induced by internally displaced person (IDP) camps in the Darfur region, Sudan, based on multitemporal MODIS data. Int. Journal of Remote Sensing, 36 (1), 190-210.

Kranz, O., Lang, S., Tiede, D., Zeug, G., Kemper, T., Caspard, M. \& Clandillon, S. (2010), GMES Services for Conflict Prevention and Mitigation: Supporting the DG RELEX in Mission Planning. In: KoneCnY, M. et al. (Eds.), Geographic Information and Cartography for Risk and Crisis Management Towards Better Solutions, 171-188.

Olsson, L., EKLUNDH, L. \& ARDÖ, J. (2005), A recent greening of the Sahel - trends, patterns and potential causes. Journal of Arid Environments, 63, 556-566.

Schimmer, R. (2008), Tracking the Genocide in Darfur: Population Displacement as Recorded by Remote Sensing. Genocide Studies Working Paper, 36.

Seaquist, J. W., Hickler, T., Eklundh, L., Ardö, J. \& Heumann, B. W. (2009), Disentangling the effects of climate and people on Sahel vegetation Dynamics. Biogeosciences, 6, 469-477.

SpRÖHNLE, K., KRANZ, O. \& SchÖPFER, S. (2010), Abschätzung der Umweltauswirkungen von Flüchtlingslagern mit Hilfe multitemporaler Fernerkundungsdaten am Beispiel des Camps Zalingei in Westdarfur. In: Strobl, J., BlaschKe, T. \& Griesebner, G. (Eds.), Angewandte Geoinformatik 2010. Beiträge zum 22. AGIT Symposium, 697-702.

TEARFUND (2007), Darfur: Relief in a vulnerable environment. Teddington.

UNHCR (2014), UNHCR Global Trends 2013: War's Human Cost.

UNEP (2007), Sudan Post-Conflict Environmental Assessment. UNEP.

UN SUDAN (2010), Beyond Emergency Relief. Longer-term trends and priorities for UN agencies in Darfur.

Wessels, K. J., Prince, S. D., Malherbe, J., Small, J., Frost, P. E. \& van Zyl, D. (2007), Can human-induced land degradation be distinguished from the effects of rainfall variability? A case study in South Africa. J. of Arid Environments, 68 (2), 271-297.

JoInT UNEP/OCHA ENVIRONMENT UNIT (2004), Darfur Crisis. Rapid Environmental Assessment at the Kalma, Otash and Bajoum Camps.

JOINT UNEP/OCHA ENVIRONMENT UNIT (2014), Environment and Humanitarian Action. Increasing Effectiveness, Sustainability and Accountability. Version 1.1. 